\title{
Sugarcane yield and quality using soil magnetic susceptibility
}

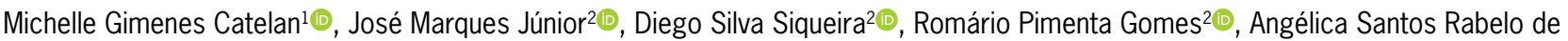 \\ Souza Bahia ${ }^{2 *}$ (1)
}

\begin{abstract}
'Usina São Martinho - Fazenda São Martinho, s/n, Rod. Dep. Cunha Bueno, km 203 - 14850-000 - Zona Rural, Pradópolis, SP - Brasil.

¿Universidade Estadual Paulista/FCAV - Depto. Ciências da Produção Agrícola, Via de Acesso Prof. Paulo Donato Castellane s/n - 14883-292 - Jaboticabal, SP - Brasil.

*Corresponding author <angelica.bahia@unesp.br>
\end{abstract}

Edited by: Paulo Cesar Sentelhas

Received October 21, 2020

Accepted March 02, 2021

\begin{abstract}
The concept of production environments, which is widely used to classify the yield potential of soils, and magnetic susceptibility (MS), is emerging as an important tool for mapping ultra-detailed areas. Given this background, this paper aims to evaluate the use of MS as a tool for the identification of areas with different potential the enhancing of sugarcane yield and quality, and the allocation of varieties. An area of 445 ha was sampled at 1 point every 7 ha, and 14 points were determined for stratified sampling following the top of the landscape. Particle size and MS of samples at depths of 0.0-0.2 and 0.2-0.4 m were analyzed. The data on yield and quality of raw material were obtained from a nine crop season database and biometry performed in the 2018/19 crop season. The multivariate analysis of historical results showed the formation of three groups with different yield and quality potential, with a difference of up to $17.28 \mathrm{mg}$ of cane per hectare between the group with the highest and lowest potential, based on soil MS. An analysis of the performance of the varieties involved showed that MS is effective in identifying areas with different potential for sugarcane yield and quality, differentiating by up to $34.5 \%$ the performance of the same variety in different MS classes and by up to $38.5 \%$ the performance of different varieties in similar MS classes. Thus, MS is an effective tool for identifying areas with different potential for sugarcane yield and quality, and can be used for allocating varieties in the field.
\end{abstract}

Keywords: Saccharum officinarum, variety, pedometry, precision agriculture

\section{Introduction}

Physical, chemical, and biological soil attributes should be considered in the context of their insertion into the landscape to understand the interaction between soils and agricultural yield (Wilding and Drees, 1983). Advances in genetic improvement allow for the development of varieties with high potential for yield and quality, and this result is directly related to its correct allocation in edaphoclimatic environments (Nass et al., 2012). Several factors interfere with sugarcane production and maturation with emphasis on edaphoclimatic interactions, crop management, and cultivar. Thus, mapping specific management zones is important for the best allocation of varieties.

The concept of production environment is defined as a physical space mapped based on edaphoclimatic characteristics for the expression of the genetic potential of the crop (Maule et al., 2001). The generation of thematic maps of production environments is based on soil surveys (taxonomic) with specific purpose of use, aimed at the location of varieties and management of sugarcane. Regions in the field with similar characteristics are known as management zones (MZ). These can be defined as subregions in a given area within which seasonal differences in weather, soil, and management are expected to have more or less uniform effects on the crops planted there (Castrignano et al., 2010). Therefore, a specific application of $\mathrm{MZ}$ is the mapping of their limits in the field, identifying areas of similar productivity potential, known as "productivity zones" or "yield zones" (Kitchen et al., 2005). These zones facilitate the appropriate management, presenting an important tool for precision agriculture.

However, studies on spatial variability require a high number of samples and increase the cost and time for field collection and laboratory analysis (Bahia et al., 2017). Magnetic susceptibility (MS) meets this need. MS was used in the first qualitative characterization studies of soils in the state of São Paulo (Siqueira et al., 2010; Barrios et al., 2012; Marques Jr. et al., 2014; Bahia et al., 2017; Camargo et al., 2018). It is an important tool that assists in defining different compartments, i.e.,, homogeneous zones for minimally representative sampling and mapping of sugarcane yield and quality potential (Craik, 1995). Stratified sampling (minimally representative) is only effective when geological variability, landscape shape, and soil type of each compartment are known (Franzen et al., 1998), since they influence the content and type of minerals which, in turn, govern the physical and chemical properties of tropical soils (Ghidin et al., 2006).

Therefore, considering that sugarcane varieties are responsive to different soil attributes influenced by the clay fraction and thus, expressed through MS, this study aims to evaluate the use of MS as a tool for identifying areas with differing potential for sugarcane yield and quality, and allocation of varieties.

\section{Materials and Methods}

\section{Location and characterization of the study area}

The study was conducted in the municipality of Luis Antônio, in the state of São Paulo (Figure 1A), in an area 
under sugarcane cultivation for more than nine years with mechanized harvesting. The study area is located at the following geographical coordinates: $\left(21^{\circ} 34^{\prime} 34.69^{\prime \prime} \mathrm{S}\right.$, $47^{\circ} 40^{\prime} 10.41^{\prime \prime} \mathrm{W}$, altitude of $648 \mathrm{~m}$ ). The regional climate is humid subtropical (Cwa), according to Köppen's classification with dry winters $(\mathrm{w})$ and hot summers (a) (Alvares et al., 2013), and average precipitation of 1400 $\mathrm{mm}$ concentrated from Nov to Feb. This area is located in the geomorphological province of the Western Plateau of São Paulo, near the limit of the Basaltic Cuestas in the sandstone-basaltic lithostratigraphic divisor.

Three geological formations were verified in the experimental area: sandstones of Botucatu Formation, basalts of Serra Geral Formation, both from São Bento Group, and Colluvial-Alluvial Deposit (Figure 1C). Botucatu Formation consists of pinkish and reddish, conglomeratic sandstones, with a uniform winddeposited formation, while Serra Geral Formation is represented by basalts and diabases.

The soils in the experimental area were classified according to the Brazilian Classification (SiBCS) and Soil Taxonomy (Soil Survey Staff, USDA, 2014). RQod (Dystrophic Ortic Quartzaren Neosol, Typic Quartzipsamment), LVd1, LVd2, LVd3 and LVd4 (Dystrophic Red Latosol (LVd), Typic Hapludox) and LVdf1 and LVdf2 (Dystroferric Red Latosol (LVdf), Typic Hapludox) (Figure 1D).

\section{Stratified sample planning}

The study area is influenced by geological and geomorphological (landscape) environmental variables, allowing for stratified sampling at strategic locations using a lower number of samples and ensuring the representativeness of the area (Siqueira et al., 2014). The grid for sample planning in the geological transition region between basalt and Colluvial-Alluvial Deposit was selected using the methodology developed in other studies (Siqueira et al., 2014; Bahia et al., 2017). The sampling density (one point every 7 ha) used was determined by following the principles of geostatistical analysis regarding the need for at least 50 pairs of points for each experimental semivariance calculation (Goovaerts, 1997).

A sampling arrangement of 88 points in the 445-ha experimental area was established (Figure 1B). At each point on the sampling grid, surface soil samples were collected with an auger at depths of 0.0-0.2 and 0.2-0.4 $\mathrm{m}$ to determine the soil attributes. Next, a stratified sampling exercise was carried out, where 14 surface soil samples (0.0-0.2 and 0.2-0.4 m) were collected with an auger throughout the transect following the top of the landscape along the cultivated area to obtain samples in the different soil classes.

\section{Soil and plant analyses}

Soil particle size analysis was determined by the pipette method (Day, 1965). Magnetic susceptibility (MS) was determined in the laboratory on air-dried fine soil, using $2 \mathrm{~cm}^{3}$ of sample in an MS2 susceptibility meter from Bartington coupled to an MS2B laboratory sensor at a low frequency $(0.47 \mathrm{kHz})$ (Dearing, 1999; Costa et al., 1999). The MS values were divided into classes: High $(\geq$ $\left.38.1 \times 10^{-6} \mathrm{~m}^{3} \mathrm{~kg}^{-1}\right)$, Intermediate $\left(19.3-38.0 \times 10^{-6}\right.$ $\left.\mathrm{m}^{3} \mathrm{~kg}^{-1}\right)$ and Low $\left(\leq 19.2 \times 10^{-6} \mathrm{~m}^{3} \mathrm{~kg}^{-1}\right)$.

According to Landell and Silva (1995), agricultural productivity can be estimated by biometric parameters. Components of sugarcane productivity are considered the diameter and length of the stems, the number of stems per area - associated with the tillering capacity, and the stalk density. All of them are genetic characters, however, subject to environmental influence. Historical data on yield and quality were obtained from the sugarcane mill database for nine crop seasons.

The biometry was used to obtain the yield results at stratified sample points (Landell and Silva, 1995). For this, sugarcane plants were collected at each of the 14 points determined by stratified sampling, with three replications with a distance of $2 \mathrm{~m}$, totaling 42 plant collections. Tillers were counted in these plants, which were cleaned and weighed.

The technological analysis that measures raw material quality reflects the performance of sugarcane juice extraction, fermentation, and distillation operations to obtain the final product (sugar and ethanol). Thus, stalks were directed to the laboratory for analysis.

The classification methods of production environments used in Brazil are taken from Sugarcane Technology Center (CTC) program (Table 1), with an average yield of four harvests. According to CTC, the study area was classified in production environments $\mathrm{C}$, $\mathrm{D}$, and $\mathrm{E}$ (Figure 1E).

\section{Mathematical modeling, statistics, and multivariate analysis}

Descriptive statistics were applied to the data using the Minitab Release 18 statistical software package to analyze the mean, median, minimum, maximum, standard deviation, skewness, kurtosis, and coefficient

Table 1 - Expectation sugarcane stalk yield $\left(\mathrm{mg} \mathrm{ha}^{-1}\right)$ of the production environments by Sugarcane Technology Center (CTC) classification method.

\begin{tabular}{lc}
\hline Environment & Stalk yield \\
\hline A1 & $\mathrm{mg} \mathrm{ha}^{-1}$ \\
A2 & $>100$ \\
B1 & $96-100$ \\
B2 & $92-96$ \\
C1 & $88-92$ \\
C2 & $84-88$ \\
D1 & $80-84$ \\
D2 & $76-80$ \\
E1 & $72-76$ \\
E2 & $68-72$ \\
\hline
\end{tabular}


A

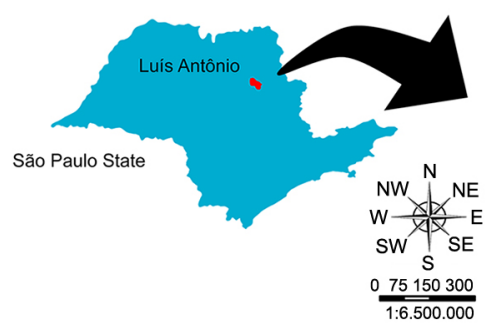

D

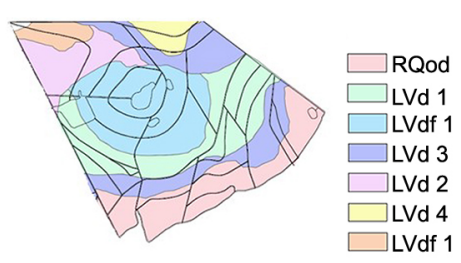

B

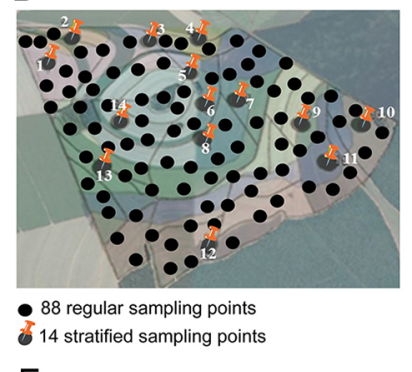

E

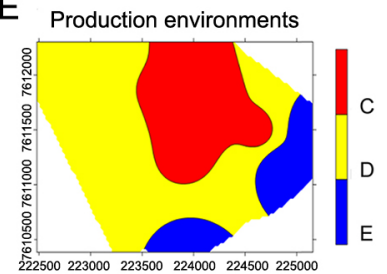

C

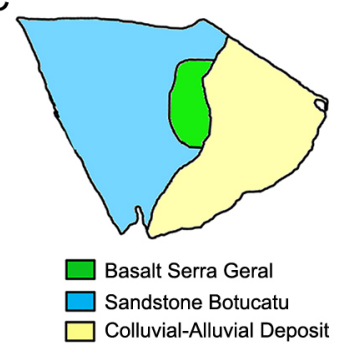

Figure 1 - (A) Study area location; (B) Map of study area indicating regular and stratified sample points; (C) Geological map of the study area (IPT, 1981); (D) Pedological map of the study area: RQod = Dystrophic Ortic Quartzaren Neosol (RQod), Typic Quartzipsamment LVd1, LVd2, LVd3 and LVd4 = Dystrophic Red Latosol (LVd), Typic Hapludox LVdf1 and LVdf2 = Dystroferric Red Latosol (LVdf), Typic Hapludox; (E) Map of production environments of the study area - C, D, and E (Sugarcane Technology Center, CTC).

of variation. The attributes' spatial variability was evaluated using geostatistics, in which the experimental variogram was estimated under the hypothesis of stationarity by Eq. (1):

$\hat{\gamma}(h)=\frac{1}{2 N(h)} \sum_{i=1}^{N(h)}\left[Z\left(x_{i}\right)-Z\left(x_{i}+h\right)\right]^{2}$

where $\gamma(h)$ is the semivariance value for a distance $h, N(h)$, the number of pairs used to calculate the semivariance, $Z\left(x_{i}\right)$, the value of attribute $Z$ at position $x i$, and $Z\left(x_{i}+h\right)$, the value of attribute $Z$ separated by a distance $h$ from position $x_{i}$.

Permissible mathematical models were adjusted to variograms, and experimental variograms were estimated to obtain the values of the nugget effect $\left(C_{0}\right)$, sill $\left(C_{0}+C_{1}\right)$, and range (a). The data were based on the pairs involved in the calculation of each point of the experimental variogram based on the sum of squared residuals (SSR), sill estimate, and coefficient of determination $\left(\mathrm{R}^{2}\right)$. The estimation of distribution of values of the variables for unsampled grid points was performed by ordinary kriging using the Surfer software package (Surfer for Windows, 1999).

To perform the multivariate analysis, the data were standardized to allow each variable to have a zero mean and unit variance. Next, they were subjected to two multivariate statistical approaches: first, cluster analysis by the hierarchical method, to divide the studied parameters into groups of greater similarity and second, Euclidean distance, used as a similarity coefficient, and Ward's method as an algorithm for linking clusters (Sneath and Sokal, 1973). According to the principal component analysis (PCA), the purpose was to verify the relationship between the attributes of the soil and the plant with the production environments. Each pair of main components (PCs) generated a twodimensional representation of the original sample space, called biplot, in which the structures of the variables can be explained by directing the beam characteristics in the regions of maximum variation.

The average contents of plant attributes in each identified group were compared by the Tukey test at $5 \%$ probability.

The Python 3.6 programming language was used to adjust the contour chart to observe the behavior of the dependent variable in relation to two independent variables together. Third-Order multivariate polynomial regression was applied.

\section{Results and Discussion}

\section{Characterization and spatialization of soil and plant attributes}

Yield and quality results from the historical database are based on a weighted average from the first to the seventh cutting stage during nine different crop seasons and are covered by five sugarcane varieties: CTC9005HP, RB855156, RB867515, CTC2, and SP832847 in all areas. Biometric results, on the other hand, are based on the arithmetic mean from the first to the third cutting stage during a single crop season and contemplated by the varieties CTC9005HP and RB855156.

An initial comparison between attributes and data heterogeneity verification can be performed by means of the coefficient of variation (CV). According to the classification of Warrick and Nielsen (1980), all soil attributes presented high $\mathrm{CV}$ values $(\mathrm{CV} \geq 24 \%)$ (Table 2). In the plant 
Table 2 - Descriptive statistics of the studied attributes.

\begin{tabular}{|c|c|c|c|c|c|c|c|c|}
\hline & Mean & Median & Min & Max & SD & Skew & Kurt & $\mathrm{CV}$ \\
\hline & \multicolumn{8}{|c|}{ Soil attributes } \\
\hline & \multicolumn{8}{|c|}{$0.0-0.2 \mathrm{~m}$} \\
\hline $\mathrm{MS}_{\mathrm{LF}}\left(10^{-6} \mathrm{~m}^{3} \mathrm{~kg}^{-1}\right)$ & 19.47 & 13.28 & 0.51 & 57.0 & 17.81 & 0.65 & -0.90 & 91.48 \\
\hline Clay $\left(\mathrm{g} \mathrm{kg}^{-1}\right)$ & 267.7 & 239.0 & 76.0 & 642.0 & 146.1 & 0.65 & -0.58 & 54.58 \\
\hline \multirow[t]{2}{*}{ Sand $\left(\mathrm{g} \mathrm{kg}^{-1}\right)$} & 639.9 & 708.3 & 193.34 & 907.8 & 221.3 & -0.58 & -1.01 & 34.58 \\
\hline & \multicolumn{8}{|c|}{$0.2-0.4 \mathrm{~m}$} \\
\hline $\mathrm{MS}_{\mathrm{LF}}\left(10^{-6} \mathrm{~m}^{3} \mathrm{~kg}^{-1}\right)$ & 19.78 & 13.17 & 0.0 & 59.48 & 18.37 & 0.68 & -0.82 & 92.87 \\
\hline Clay $\left(\mathrm{g} \mathrm{kg}^{-1}\right)$ & 317.9 & 292.0 & 59.0 & 625.0 & 159.0 & 0.33 & -1.10 & 50.01 \\
\hline \multirow[t]{2}{*}{ Sand $\left(\mathrm{g} \mathrm{kg}^{-1}\right)$} & 628.6 & 685.3 & 203.5 & 932.5 & 214.9 & -0.55 & -0.98 & 34.18 \\
\hline & \multicolumn{8}{|c|}{ Plant attributes - historical } \\
\hline Stalk yield & 87.57 & 92.39 & 72.32 & 96.85 & 8.23 & -0.72 & -0.93 & 9.40 \\
\hline TRS & 129.85 & 130.27 & 126.75 & 132.17 & 1.42 & -0.94 & 0.42 & 1.09 \\
\hline Pol & 15.77 & 15.88 & 15.14 & 16.05 & 0.24 & -1.57 & 1.33 & 1.57 \\
\hline Brix & 18.31 & 18.39 & 17.81 & 18.58 & 0.21 & -1.42 & 0.93 & 1.15 \\
\hline \multirow[t]{2}{*}{ Fiber } & 13.68 & 13.77 & 13.03 & 14.08 & 0.22 & -1.73 & 3.69 & 1.62 \\
\hline & \multicolumn{8}{|c|}{ Plant attributes - biometry } \\
\hline Stalk yield & 88.34 & 88.03 & 54.54 & 122.67 & 21.35 & 0.26 & -0.31 & 24.17 \\
\hline TRS & 146.11 & 143.40 & 139.88 & 155.08 & 5.64 & 0.35 & -1.78 & 3.86 \\
\hline Pol & 17.25 & 17.25 & 16.25 & 18.47 & 0.74 & 0.12 & -1.35 & 4.32 \\
\hline Brix & 19.56 & 19.52 & 18.70 & 20.55 & 0.59 & -0.03 & -1.05 & 3.06 \\
\hline Fiber & 11.74 & 11.76 & 10.58 & 12.80 & 0.70 & -0.01 & -0.89 & 6.01 \\
\hline
\end{tabular}

Min = minimum; Max = maximum; $\mathrm{SD}=$ standard deviation; Skew = skewness; Kurt = kurtosis; $\mathrm{CV}=$ coefficient of variation; $\mathrm{MS}_{\mathrm{LF}}=$ low-frequency magnetic susceptibility; TRS = total recoverable sugar; Pol = mass percentage of apparent sucrose; Brix = mass percentage of soluble solids.

attributes, the historical and biometric results presented a low CV value $(\leq 12 \%)$, except the stalk yield (obtained by biometrics) which presented a high $\mathrm{CV}$ value. It was observed that the CV of the MS at both depths is higher than the $\mathrm{CV}$ values of clay and sand. However, the spatial variability analysis by geostatistics can help to understand this range of variation.

The average stalk yield $\left(\mathrm{mg} \mathrm{ha}^{-1}\right)$ by historical data and biometry are similar; however, the historical stalk yield ranged from 72.3 to 96.8 , while the result through biometry in the 2018/19 crop season ranged from 54.5 to 122.6. The average contents of total recoverable sugar (TRS) and mass percentage of apparent sucrose (Pol) obtained by biometry are higher when compared to the historical data. It is worth mentioning that, in the technological analysis, the methodology via biometry considers the clean sugarcane stalk, different from the methodology using historical data, which comes from the survey conducted by the industry (Table 2).

All attributes presented spatial dependence structure, expressed through variogram adjustments. The spherical model was adjusted to the experimental variograms for all attributes (Figure 2). Cambardella et al. (1994) reported that the spherical model is the model that is most adapted to describe the performance of plant and soil attributes semivariograms. In addition to being recommended for describing properties with abrupt changes across the landscape (Isaaks and Srivastava, 1989), this study corroborates the findings of other researchers (Trangmar et al., 1985; McBratney and Webster, 1986; Bahia et al., 2015; 2017).
The nugget effect is an important variogram parameter that indicates unexplained variability, considering the sampling distance used (McBratney and Webster, 1986). According to the Cambardella et al. (1994) classification,spatial dependence is considered strong when variograms have a nugget effect $\leq 25 \%$ of sill, moderate when the nugget effect is between 25 and $75 \%$, and weak when it is > $75 \%$. All variograms fall into the class of strong spatial dependence.

According to the maps of soil attributes presented in Figure 3, there is a strong spatial relationship between magnetic susceptibility and clay and sand contents, at both depths. It was observed that the regions with the highest MS values are those with the highest clay and lowest sand contents. A similarity was also observed between the maps of the depths of 0.0-0.2 $\mathrm{m}$ and 0.2$0.4 \mathrm{~m}$ are similar, which demonstrates an important characteristic of the Oxisols in terms of profile homogeneity. Even though the surface layer is subject to agricultural management practices, the granulometry and magnetic signature values are maintained. As for the spatial distribution maps for plant attributes (Figure 4) via historical data from nine crops, it was observed that the areas with the highest productivity on the map corresponded to those with high clay and MS values.

MS is related to physical, chemical and mineralogical soil attributes, such as clay content and iron oxides (Torrent et al., 2007). According to Grimley et al. (2004), MS is affected by the soil's surface texture processes that lead to clay formation, common in tropical regions, and contribute to higher MS values. Therefore, 

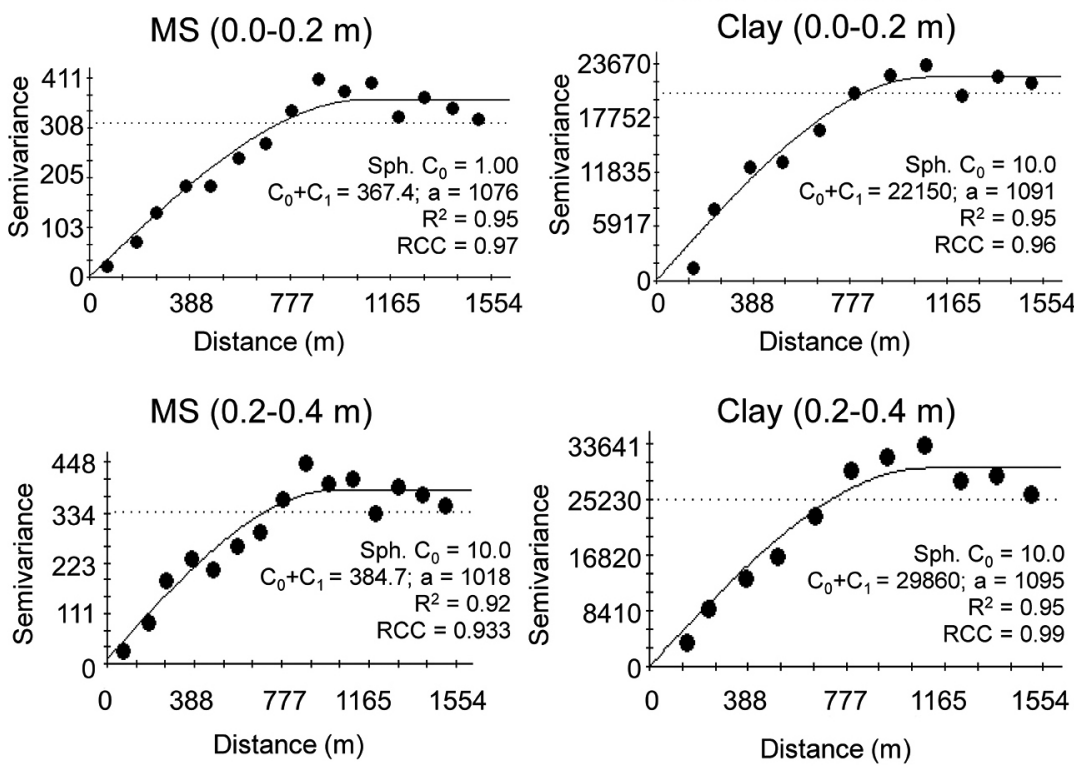

Clay (0.0-0.2 m)

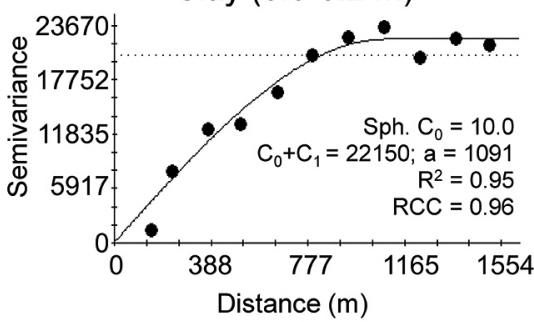

Clay $(0.2-0.4 \mathrm{~m})$
Soil Attributes

Plant Attributes

Stalk yield

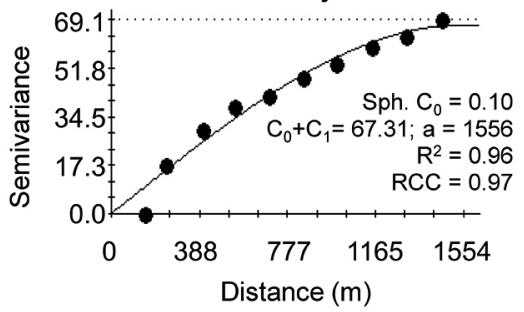

Brix

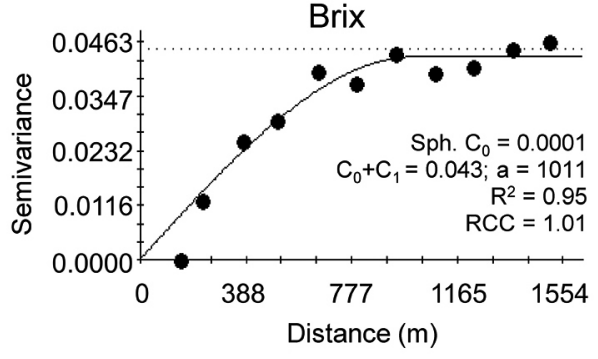

TRS

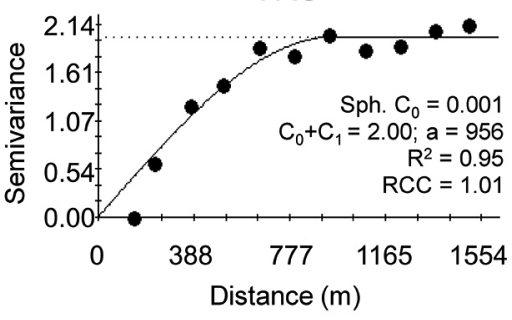

Fiber

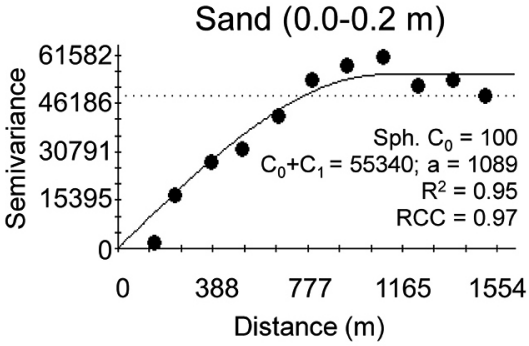

Sand (0.2-0.4 m)

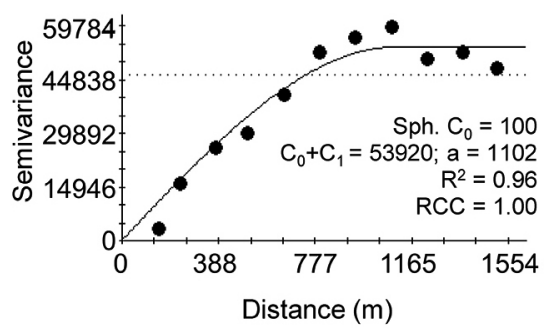

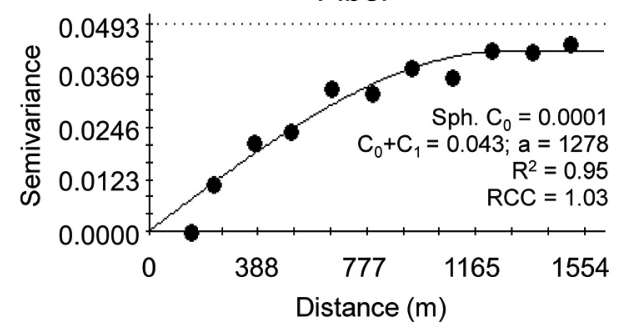

Figure 2 - Variograms of soil and plant attributes. MS = magnetic susceptibility; TRS = total recoverable sugar; Pol = mass percentage of apparent sucrose; Brix = mass percentage of soluble solids; Sph. = spherical model; $C_{0}=$ nugget effect; $C_{0}+C_{1}=$ sill; $C_{0} /\left(C_{0}+C_{1}\right)=$ degree of spatial dependence; $\mathrm{a}=$ range distance $(\mathrm{m}) ; \mathrm{RCC}=$ regression coefficient of cross-validation.

since MS is a covariate attribute of soil formation factors and processes and source materials (Maher and Thompson, 1999; Mullins, 1977; Torrent and Barrón, 1993), it can be considered as a pedoindicator for mapping environments (Bahia et al., 2017). In addition, obtaining it is much faster and cheaper than obtaining the clay in the laboratory.

Bahia et al. (2017) conclude that the prediction of clay by MS can assist in the identification and mapping of homogeneous management zones in soils under the
Serra Geral Formation, Colluvial-Elluvial Deposit and Alluvial Deposit. In addition, these authors observed that for highly weathered soils, such as ferric Oxisols, MS is suited to assisting in attribute prediction, making it a very useful tool. Siqueira et al. (2010) using MS in pedotransfer functions found strong correlations for clay contents $(r=0.68)$, concluding that MS has the potential to help characterize the variability of soil attributes in large areas. Teixeira et al. (2018) observed that the incorporation of information from maps of MS 

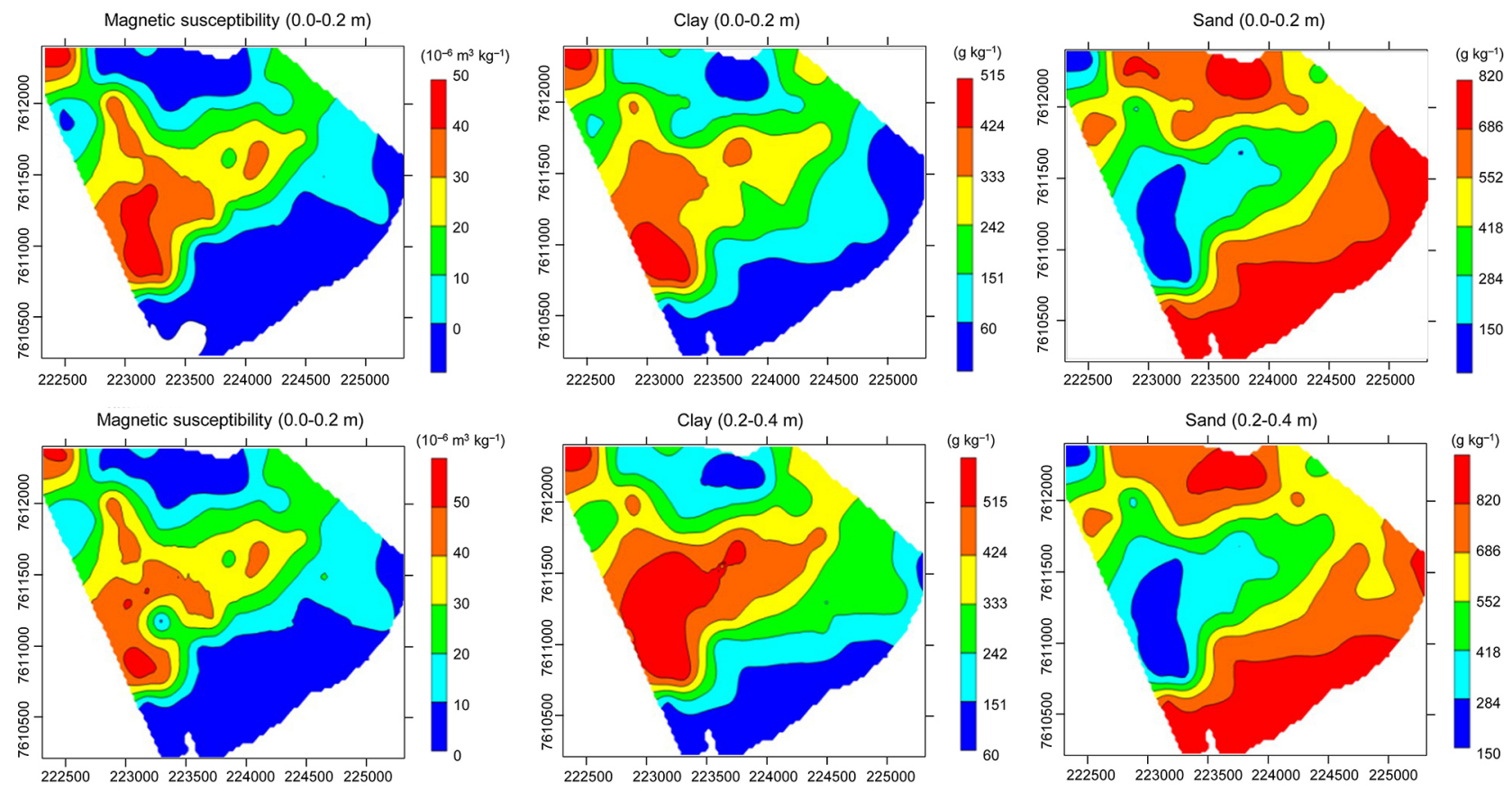

Figure 3 - Spatial distribution maps of soil attributes.

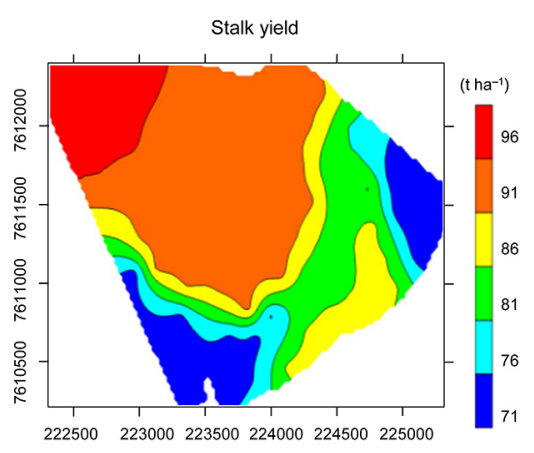

Brix

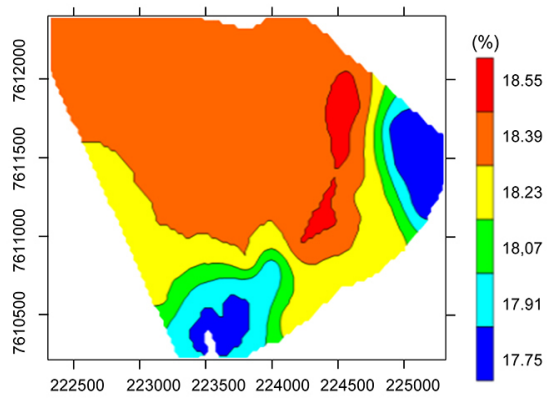

TRS

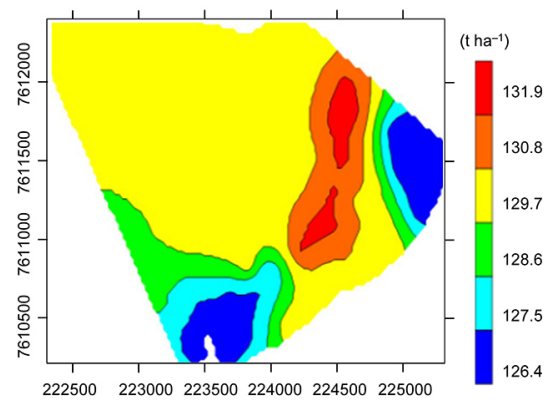

Fiber

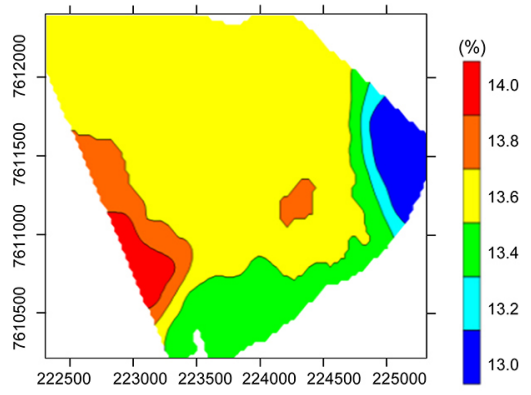

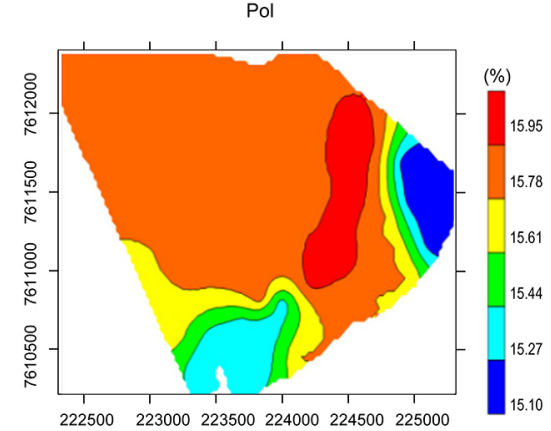

Figure 4 - Spatial distribution maps for plant attributes via historical data from nine crops.

and clay content in delineating mapping units allows for the incorporation of information on spatial variability of soil attributes to the delineated map. Despite this, MS is an excellent tool which assists in the development of management zones, since its application is quick, easy and low cost.
Identification of areas with different yield and quality potential by multivariate statistical technique

The distinction of landscape compartments in the principal component analysis was similar to that of 


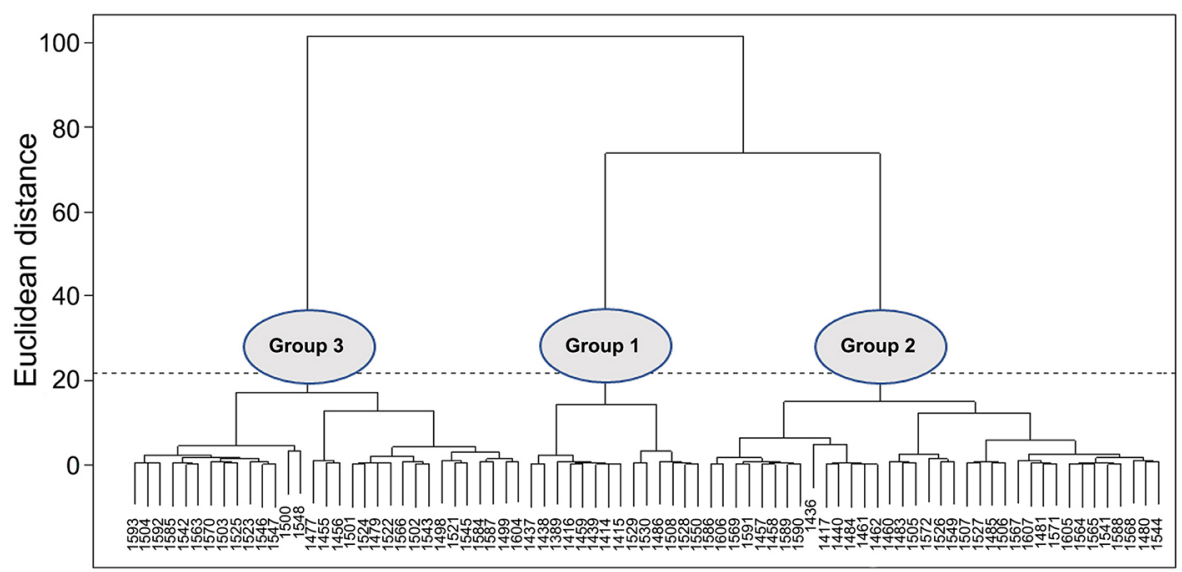

Figure 5 - Dendrogram of hierarchical cluster analysis showing the formation of three groups according to the studied attributes, identified as Group 1, Group 2, and Group 3.

the group formed in the cluster analysis using only the attributes of highest discriminatory power (Figures 5 and 6). The submission of data to cluster analysis allowed for the formation of three groups that agree with the division of compartments established in the field.

Grouping observed in the cluster analysis highlights the possibility that MS can be used as a tool that facilitates the identification of the landscape compartment and enables the mapping of more homogeneous areas in similar places. Similar potential results were found by Barrios et al. (2012), in which the submission of the data to cluster analysis allowed for the formation of two groups, which coincide with the division of different soil quality conditions.

The dendrogram obtained by the hierarchical cluster analysis is shown in Figure 5. Each time significant changes in Euclidean distance values occur between records defined as sampling points in the studied land uses, it can be related to the formation of similar accession groups, regardless of the depth of analysis (0.0-0.2 and 0.2-0.4 m).

The values of the Euclidean distance for the 11 studied attributes were 25 (Figure 5). The cluster analysis based on the soil and plant attributes of all sampling points produced three distinct groups (Group 1, Group 2 and Group 3). Differences were observed by the Tukey test at $5 \%$ probability for the average results of sugarcane attributes (Stalk yield, TRS, Pol, Brix, and Fiber) between Groups 3 and 1, Group 2 being statistically similar to Group 3 (Table 3 ).

Magnetic susceptibility values were classified as high ( $\geq 38.1$ ), intermediate (19.3-38.0), and low $(\leq 19.2)$ to characterize the groups identified by the multivariate analysis. As shown in Table 4, the percentage distribution between high, intermediate, and low MS values was characterized for each group identified by the multivariate analysis. Magnetic susceptibility is an important factor to identify areas with different yield and quality potentials. Thus, Group 3 shows the highest

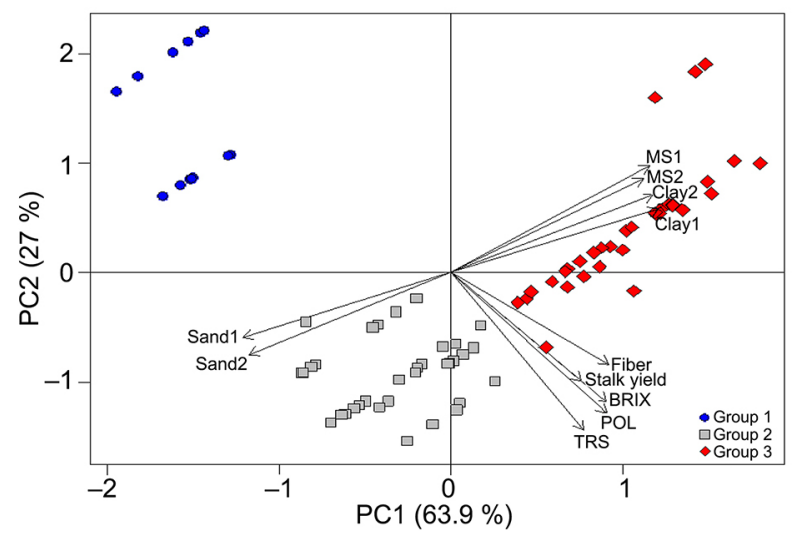

Figure 6 - Biplot chart of the first and second principal components of PCA with all evaluated observations. $\mathrm{MS1}=0.0-0.2 \mathrm{~m}$ magnetic susceptibility; MS2 = 0.2-0.4 m magnetic susceptibility; Clay1 = 0.0-0.2 m clay content; Clay2 $=0.2-0.4$ m clay content; Sand $1=$ 0.0-0.2 m sand content; Sand2 $=0.2-0.4 \mathrm{~m}$ sand content; TRS $=$ total recoverable sugar; $\mathrm{Pol}=$ mass percentage of apparent sucrose; Brix $=$ mass percentage of soluble solids. Group $1=$ low yield, Group 2 = intermediate yield, and Group 3 = high yield.

Table 3 - Average of plant attributes in the three identified groups.

\begin{tabular}{lccccc}
\hline & Stalk yield & TRS & Pol & Brix & Fiber \\
\cline { 2 - 6 } & \multicolumn{5}{c}{ Plant attributes } \\
\hline Group 1 & $73.99 \mathrm{~b}$ & $127.08 \mathrm{~b}$ & $15.26 \mathrm{~b}$ & $17.87 \mathrm{~b}$ & $13.29 \mathrm{~b}$ \\
Group 2 & $89.64 \mathrm{a}$ & $130.56 \mathrm{a}$ & $15.87 \mathrm{a}$ & $18.40 \mathrm{a}$ & $13.73 \mathrm{a}$ \\
Group 3 & $91.27 \mathrm{a}$ & $130.18 \mathrm{a}$ & $15.86 \mathrm{a}$ & $18.39 \mathrm{a}$ & $13.80 \mathrm{a}$ \\
CV (\%) & 6.3 & 0.5 & 0.5 & 0.4 & 0.9 \\
\hline
\end{tabular}

Means followed by the same letters do not differ from each other by the Tukey test at $5 \%$ probability. TRS $=$ total recoverable sugar; $\mathrm{Pol}=$ mass percentage of apparent sucrose; Brix = mass percentage of soluble solids; $\mathrm{CV}=$ coefficient of variation.

yield results and high and intermediate MS classes (Tables 4 and 5). On the other hand, Group 1 had the lowest yield results and low MS class. 
The results of the principal component analysis (Figure 6) to verify the formation of groups observed in the hierarchical cluster analysis indicate that $63.9 \%$ of the total variability was explained by the first principal component (PC1). The second principal component (PC2), on the other hand, explained $27 \%$ of the total variability, totaling $91 \%$ of the variability of the original data. This amount of explained variation was sufficient to generate the same three groups observed in the previous analysis.

In PC1, the characteristics with the highest correlation coefficients were Sand 1 and 2 (-0.92 and -0.90 , respectively), Clay 1 and 2 (0.92 and 0.90, respectively), and MS 1 and 2 (0.88 and 0.86, respectively). This component can be interpreted as the contrast between clay and MS with sand, which we can see in the spatial variability maps, where high clay values coincide with high MS values and lower sand values (Figure 3).

Stalk yield and fiber present the highest discriminant power in PC1 (0.58 and 0.70, respectively). $\mathrm{PC} 2$, in turn, has only the production variable, expressed by stalk yield, TRS, Pol, Brix, and Fiber, with correlation coefficients values of $-0.54,-0.74,-0.71,-0.70$, and -0.46 , respectively. Therefore, stalk yield has influence in both components.

Figure 7 shows the strong spatial relationship of the points of each cluster of the multivariate analysis with magnetic ranges of the study area expressed on the map. Group 1 is located in the region with the lowest MS, representing the lowest values for sugarcane attributes. Group 2 is positioned in the intermediate MS region, representing average results for sugarcane attributes, but not statistically different from those of Group 3, which, in turn, is located in the region with the highest MS and, therefore, has the best results for sugarcane attributes.

Similar results were found by Marques Jr. et al. (2014), who, when analyzing the correlation of soil attributes and sugarcane properties with MS, observed

Table 4 - Percentage distribution between high, intermediate, and low MS values for each group identified by the multivariate analysis.

\begin{tabular}{lccc}
\hline MS class & Group 1 & Group 2 & Group 3 \\
\hline High $(\geq 38.1)$ & 0 & 0 & $51.6 \%$ \\
Intermediate (19.3-38.0) & 0 & $8.3 \%$ & $48.4 \%$ \\
Low $(\leq 19.2)$ & $100 \%$ & $91.7 \%$ & 0 \\
\hline
\end{tabular}

$\mathrm{MS}=$ magnetic susceptibility $\left(10^{-6} \mathrm{~m}^{3} \mathrm{~kg}^{-1}\right)$.

Table 5 - Average plant attributes and MS for each variety.

\begin{tabular}{lrccc}
\hline Variety & MS & Stalk yield & TRS & TSH \\
\hline RB855156 & 2.08 & 68.68 & 145.26 & 9.98 \\
RB855156 & 33.17 & 89.98 & 149.17 & 13.42 \\
CTC9005HP & 6.38 & 97.17 & 142.25 & 13.82 \\
CTC9005HP & 30.38 & 121.44 & 141.05 & 17.13 \\
\hline
\end{tabular}

MS = magnetic susceptibility $\left(10^{-6} \mathrm{~m}^{3} \mathrm{~kg}^{-1}\right) ;$ TRS = total recoverable sugar; $\mathrm{TSH}=\mathrm{mg}$ of sugar per hectare. that clay has positive correlation with MS, as well as Yield, Brix, Pol \%, Fiber and TRS have positive correlation with MS. According to these authors, MS can be used to identify sites with different potential related to the production of sugarcane, corroborating the results found in the present study.

\section{Use of magnetic susceptibility for variety allocation}

Yield and quality results of biometry data by magnetic amplitude from class 1 to 5 (lowest to highest magnetic susceptibility) at a depth of 0.0-0.2 m (Figure 8) shows that yield in class 5 was higher than that observed in other classes. As regards TRS and Pol, class 4 was superior to the others. In the TSH index, class 5 was superior to other classes.

The highest MS class corresponds to the highest yield class (Figure 8). Similar results were found by Siqueira et al. (2010), who observed that MS was spatially correlated with soil and plant attributes and concluded that it could be used to assist in mapping specific management areas for sugarcane.

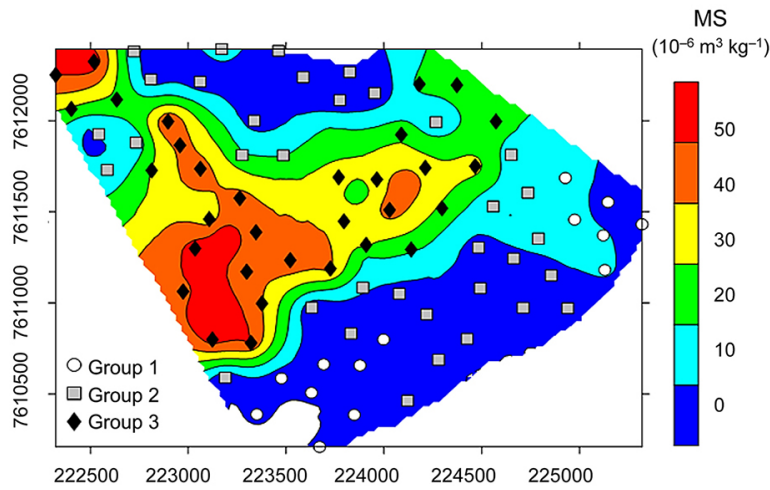

Figure 7 - Overlap of the three clusters of identified attributes to the 0.0-0.2 m magnetic susceptibility (MS) mapping of the study area. Group 1 = low yield, Group 2 = intermediate yield, and Group $3=$ high yield .

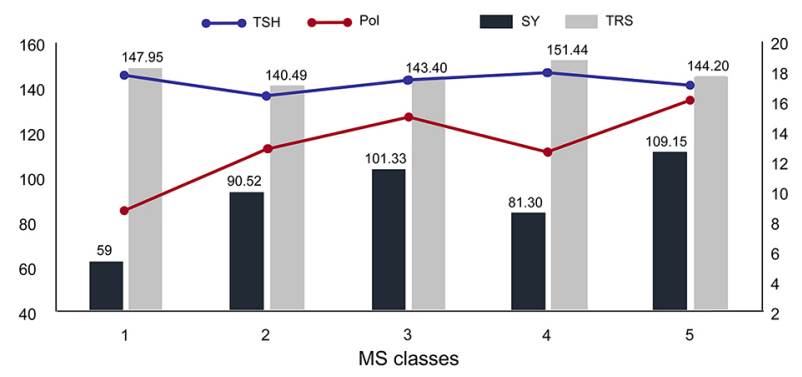

Figure $\mathbf{8}$ - Results of biometry by magnetic amplitude at a depth of 0.0-0.2 m. SY = stalk yield $\left(\mathrm{t} \mathrm{ha}^{-1}\right)$; TRS = total recoverable sugar $\left(\mathrm{kg} \mathrm{t}^{-1}\right) ; \mathrm{Pol}=$ mass percentage of apparent sucrose $(\%) ; \mathrm{TSH}=$ $\mathrm{Mg}$ of sugar per hectare $\left(\mathrm{mg} \mathrm{ha}^{-1}\right)$. Class $1=$ very low MS, Class 2 = low MS, Class 3 = intermediate MS, Class $4=$ high MS, and Class $5=$ very high MS. 
Barrios et al. (2012) also observed that MS can be used as a geophysical quality indicator in environments under sugarcane management systems, and may be a study tool for the detailed characterization of special variability over large areas. Magnetic information also helps in identifying areas where Pol and stalk yield values are below expectations, signaling the interference of environmental and management factors that are influencing the result (Marques Jr. et al., 2014).

Studies carried out by Melo (2006) inferred that sugarcane stalk yield $\left(\mathrm{mg} \mathrm{ha}^{-1}\right)$ is one of the characteristics most influenced by genotype $x$ environment interaction, corroborating the variability of yield results according to the variability of the MS attribute.

Figure 9 shows the correlation between the results of stalk yield $\left(\mathrm{mg} \mathrm{ha}^{-1}\right)$, TRS, and MS of the 14 biometry points performed in the 2018 crop season. Each point in the chart is identified by MS value and variety, being $5156=\mathrm{RB} 855156$ and $9005=\mathrm{CTC} 9005 \mathrm{HP}$. Thus, the higher MS classes have higher results of sugarcane yield and quality. On the other hand, as MS class decreases, we observed higher variability in the data, but all with a tendency to lower results of yield and quality.

A number of intermediate yield results (between 72 and 90 stalk yield in $\mathrm{mg} \mathrm{ha}^{-1}$ ) were observed for high and very high MS classes, demonstrating that the allocated variety did not express its maximum potential at this location. In this context, there is an opportunity in which allocating the CTC9005HP variety instead of RB855156 could lead to higher yield. On the other hand, the higher yield of the RB855156 variety is due to the better conditions responsible for the good development of the plant, such as water availability and good soil conditions, which were represented here by high MS.

Another opportunity refers to the lower MS class, with yield for RB855156 below 60 stalk yield (mg ha-1), in which the allocation of the RB867515 variety could be evaluated, for instance, which is recommended for production environments $\mathrm{C}, \mathrm{D}$, and $\mathrm{E}$. Its main characteristic is the good yield in environments of low productive potential.

According to the results for yield and quality between the highest and lowest MS classes in the 11 biometry points (Table 5), the RB855156 variety presented 21.3 stalk yield $\left(\mathrm{mg} \mathrm{ha}^{-1}\right)$ more in points with average MS of 33.17 when compared to points of average MS of 2.08. The qualitative analysis showed $3.91 \mathrm{~kg} \mathrm{t}^{-1}$ TRS more when comparing the class of higher MS with that of the lowest MS. The variety CTC9005HP presented an increase of 24.27 stalk yield $\left(\mathrm{mg} \mathrm{ha}^{-1}\right)$ in the points with average MS of 30.38 when compared to points with average MS of 6.38 ; for the qualitative analysis, the lowest MS class had the highest result, with an increment of $1.2 \mathrm{~kg} \mathrm{t}^{-1}$ TRS. It signaled a lower response in sugar accumulation in less restrictive soils, and behavior opposite to that found at low MS points.

The highest TSH result was obtained by the CTC9005HP variety in the higher MS class, while the lowest result was observed in the RB855156 variety in the lowest MS class. Considering the same variety, the result in TSH from the lowest MS class to the highest had an increase of 34.5 and $23.9 \%$ for RB855156 and CTC9005HP, respectively. Considering similar MS classes, the results of TSH from the RB855156 variety to CTC9005HP increased by 38.5 and $27.6 \%$ for low and high MS classes, respectively.

As shown in Figure 9, considering the suggestion of allocating CTC9005HP instead of the RB855156 variety in soils with higher MS or more responsive results, there are indications of gains of 31.46 stalk yield /mg $\mathrm{ha}^{-1}$ ) according to the results obtained in the 11 points of biometry shown in Table 5 .

The analysis of variety performance in the different magnetism classes indicates an opportunity to construct management zones based on soil MS, as shown in the overlapping map of the three groups identified by the dendrogram. Since obtaining MS from soils is easier,

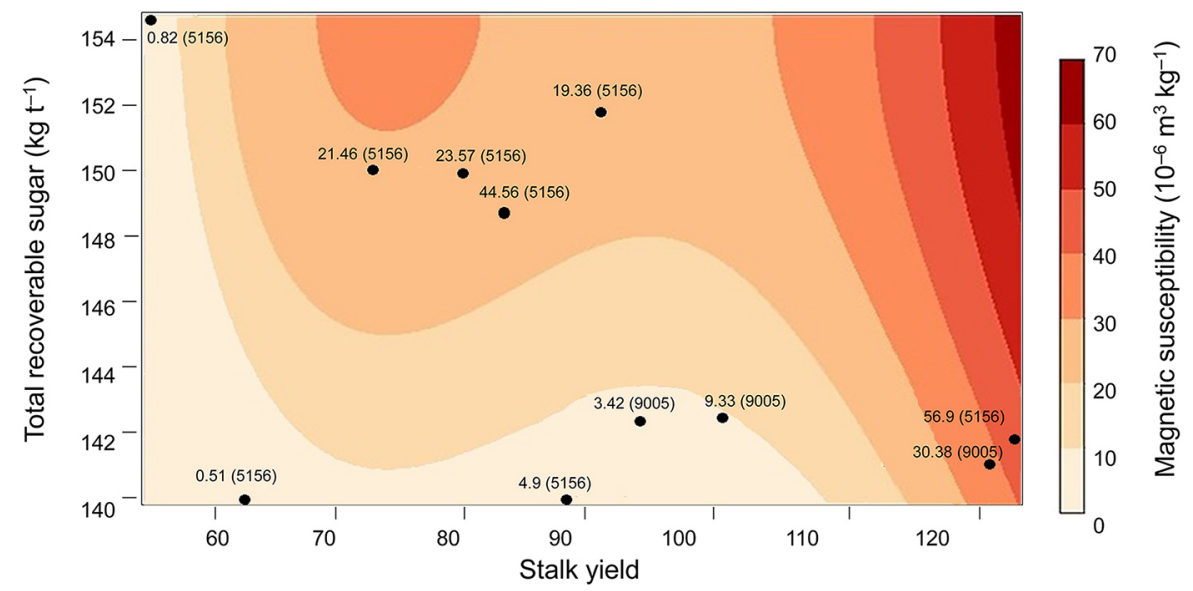

Figure 9 - Contour chart of Stalk yield attributes, TRS = total recoverable sugar, and MS = magnetic susceptibility $\left(10^{-6} \mathrm{~m}^{3} \mathrm{~kg}^{-1}\right)$. Each point in the chart is identified by MS value and variety, being $5156=$ RB855156 and $9005=$ CTC9005HP. 
practical and cheaper than obtaining other covariate attributes and indicators of soil variability, such as clay content, magnetic susceptibility becomes an efficient tool for assisting in the identification of areas of greatest productive potential, which can help in the classification of production environments already established in the sector today. It is a promising technology for practical use in sugarcane mills and suppliers.

\section{Conclusions}

The analysis of the spatial variability of soil and plant attributes, as well as the multivariate analysis managed to capture the relationship between MS with clay, sugarcane yield and quality. In the results of biometry by magnetic amplitude, the highest MS class corresponds to the area with the highest yield class. The analysis of varietal performance in the different magnetism classes indicates the opportunity to construct management zones for sugarcane growing based on MS, since its use is easier, cheaper and faster compared to obtaining other covariate attributes in the laboratory, such as clay content. Therefore, MS is an effective tool for identifying areas with different potential for sugarcane yield and quality, which can assist in the allocation of varieties in the field.

\section{Authors' Contributions}

Conceptualization: Catelan, M.G.; Marques Jr., J.; Siqueira, D.S.; Gomes, R.P.; Bahia, A.S.R.S. Data acquisition: Catelan, M.G. Data analysis: Catelan, M.G.; Siqueira, D.S.; Gomes, R.P.; Bahia, A.S.R.S. Design of methodology: Catelan, M.G.; Marques Jr., J.; Siqueira, D.S.; Bahia, A.S.R.S. Software development: Siqueira, D.S.; Gomes, R.P. Writing and editing: Catelan, M.G.; Bahia, A.S.R.S.; Gomes, R.P.

\section{References}

Alvares, C.A.; Stape, J.L.; Sentelhas, P.C.; Gonçalves, J.L.M.; Spavorek, G. 2013. Köppen's climate classification map for Brazil. Meteorologische Zeitschrift 22: 711-728.

Bahia, A.S.R.S.; Marques Jr., J.; La Scala, N.; Cerri, C.E.P.; Camargo, L.A. 2017. Prediction and mapping of soil attributes using diffuse reflectance spectroscopy and magnetic susceptibility. Soil Science Society of America Journal 81: 14501462.

Bahia, A.S.R.S.; Marques Jr., J.; Panosso, A.R.; Camargo, L.A.; Siqueira, D.S.; Teixeira, D.D.B.; La Scala, N. 2015. Field-scale spatial correlation between contents of iron oxides and $\mathrm{CO}_{2}$ emission in an Oxisol cultivated with sugarcane. Scientia Agricola 72: 157-166.

Barrios, M.R.; Marques Jr., J.; Panosso, A.R.; Siqueira, D.S.; La Scala, N. 2012. Magnetic susceptibility to identify landscape segments on a detailed scale in the region of Jaboticabal, São Paulo, Brazil. Revista Brasileira de Ciência do Solo 36: 10731082.
Camargo, L.A.; Marques Jr., J.; Barrón, V.; Alleoni, L.R.F.; Pereira, G.T.; Teixeira, D.D.B.; Bahia, A.S.R.S. 2018. Predicting potentially toxic elements in tropical soils from iron oxides, magnetic susceptibility and diffuse reflectance spectra. Catena 165: 503-515.

Cambardella, C.A.; Moorman, T.B.; Novak, J.M.; Parkin, T.B.; Karlen, D.L.; Turco, R.F.; Konopka, A.E. 1994. Field-scale variability of soil properties in Central Iowa Soils. Soil Science Society of America Journal 58: 1501-1511.

Castrignano, A.; Guastaferro, F.; De Benedetto, D.; Sollitto, D.; Troccoli, A.; Cafarelli, B. 2010. A comparison of different algorithms for the delineation of management zones. Precision Agriculture 11: 600-620.

Costa, A.C.S.; Bigham, J.M.; Rhoton, F.E.; Traina, S.J. 1999. Quantification and characterization of maghemite in soils derived from volcanic rocks in southern Brazil. Clays and Clay Minerals 47: 466-473.

Craik, D. 1995. Magnetism: Principles and Applications. John Wiley, New York, NY, USA.

Day, P.R. 1965. Particle fraction and particle fractionation and particle-size analysis. p. 545-566. In: Black, C.A., ed. Methods of soil analysis. American Society of Agronomy, Madison, WI, USA.

Dearing, J. 1999. Environmental magnetic susceptibility: using the Bartington MS2 System. 2ed. Chi Publishing, Kenilworth, UK.

Franzen, D.W.; Cihacek, L.J.; Hofman, V.L.; Swenson, L.J. 1998. Topography-based sampling compared with grid sampling in the Northern Great Plains. Journal of Production Agriculture 11: 364-370.

Ghidin, A.A.; Melo, V.F.; Lima, V.C.; Lima, J.M.J.C. 2006. Oxisol toposequences developed from basaltic rocks in Paraná State, Brazil. I. Clay fraction mineralogy. Revista Brasileira de Ciência do Solo 30: 293-306 (in Portuguese, with abstract in English).

Goovaerts, P. 1997. Geostatistics for Natural Resources Evaluation. Oxford University Press, New York, NY, USA.

Grimley, D.A.; Arruda, N.K.; Bramstedt, M.W. 2004. Using magnetic susceptibility to facilitate more rapid, reproducible and precise delineation of hydric soils in the midwestern USA. Catena 58: 183-213.

Kitchen, N.R.; Sudduth, K.A.; Myers, D.B.; Drummond, S.T.; Hong, S.Y. 2005. Delineation productivity zones on clay pan soil fields using apparent soil electrical conductivity. Computers and Electronics in Agriculture 46: 285-308.

Landell, M.G.A.; Silva, M.A. 1995. Experimenter's manual: sugarcane breeding $=$ Manual do experimentador: melhoramento da cana-de-açúcar. In: Experimentation Methodology: competition trials in sugarcane = Metodologia de experimentação: ensaios de competição em cana-de-açúcar. Instituto Agronômico, Campinas, SP, Brazil (in Portuguese).

Maher, B.A.; Thompson, R. 1999. Palaeomonsoons. I. The magnetic record of palaeoclimate in the terrestrial loess and palaeosol sequences. p. 81-125. In: Maher, B.A.; Tompson, R., eds. Quaternary climates, environments and magnetism. Cambridge University Press, Cambridge, UK.

Marques Jr., J.; Siqueira, D.S.; Camargo, L.A.; Teixeira, D.D.B.; Barrón, V.; Torrent, J. 2014. Magnetic susceptibility and diffuse reflectance spectroscopy to characterize the spatial variability of soil properties in a Brazilian Haplustalf. Geoderma 219-220: 63-71. 
Maule, R.F.; Mazza, J.A.; Martha Jr., G.B. 2001. Productivity of sugarcane cultivars in different soils and harvesting periods. Scientia Agricola 58: 295-301 (in Portuguese, with abstract in English).

McBratney, A.B.; Webster, R. 1986. Choosing functions for semivariograms of soil properties and fitting them to sampling estimates. Soil Science Society of America Journal 37: 617-639.

Melo, L.J.O.T.; Oliveira, F.J.; Bastos, G.Q.; Anunciação Filho, C.J.; Reis, O.V. 2006. Sugarcane genotype $\times$ harvest cycles interaction in Zona da Mata Norte of Pernambuco. Bragantia 65: 97-205 (in Portuguese, with abstract in English).

Mullins, C.E. 1977. Magnetic susceptibility of the soil and its significance in soil science: a review. Journal of Soil Science 28: 223-246.

Nass, L.L.; Sigrist, M.S.; Ribeiro, C.S.D.C.; Reifschneider, F.J.B. 2012. Genetic resources: the basis for sustainable and competitive plant breeding. Crop Breeding and Applied Biotechnology 12: 75-86.

Siqueira, D.S.; Marques Jr., J.; Pereira, G.T. 2010. The use of landforms to predict the variability of soil and orange attributes. Geoderma 155: 55-66.

Siqueira, D.S.; Marques Jr., J.; Pereira, G.T.; Barbosa, R.S.; Teixeira, D.D.B.; Peluco, R.G. 2014. Sampling density and proportion for the characterization of the variability of Oxisol attributes on different materials. Geoderma 232-234: 172-182.

Sneath, P.H.; Sokal, R.R. 1973. Numerical taxonomy: the principles and practice of numerical classification. W.H. Freeman, San Francisco, CA, USA.
Surfer, S. 1999. 7.0. Contouring and 3D Surface Mapping for Scientist's Engineers: User's Guide. Golden Software, New York, NY, USA.

Teixeira, D.D.; Marques Jr, J.; Siqueira, D.S.; Vasconcelos, V.; Carvalho Jr, O.A.; Martins, É.S.; Pereira, G.T. 2018. Mapping units based on spatial uncertainty of magnetic susceptibility and clay content. Catena 164: 79-87.

Torrent, J.; Liu, Q.S.; Bloemendal, J.; Barrón, V. 2007. Magnetic enhancement and iron oxides in the upper Luochuan loesspaleosol sequence on the Chinese Loess Plateau. Soil Science Society of America Journal 71: 1-9.

Torrent, J.; Barrón, V. 1993. Laboratory measurements of soil color: theory and practice. p. 21-33. In: Bigham, J.M.; Ciolkosz, E.J., eds. Soil color. Soil Science Society of America, Madison, WI, USA.

Trangmar, B.B.; Yost, R.S.; Uehara, G. 1985. Applications of geostatistics to spatial studies of soil properties. Advances in Agronomy 38: 45-94.

Warrick, A.W.; Nielsen, D.R. 1980. Spatial variability of soil physical properties in the field. p. 319-344. In: Hillel, D., ed. Applications of soil physics. Academic Press, New York, NY, USA.

Wilding, L.P.; Drees, L.R. 1983. Spatial variability and pedology. In: Pedogenesis and soil taxonomy. I. Concepts and interactions. Elsevier, New York, NY, USA. 